\title{
Parenting Skills, Family Functioning and Social Support in Situations of Child-to-Parent Violence: a Scoping Review of the Literature
}

\author{
Shirley Arias-Rivera ${ }^{1}$ (D) $\cdot$ Bárbara Lorence $^{1}$ (D) Victoria Hidalgo $^{1}$ (D)
}

Accepted: 31 August 2021 / Published online: 29 September 2021

(c) The Author(s) 2021

\begin{abstract}
The aim of this study was to carry out a scoping review to analyze the available evidence regarding parenting skills, family functioning and social support in situations of CPV. When violent behavior occurs, roles, communication and emotional expression are affected, impacting both parenting skills and family functioning. The confluence of these variables could explain the perpetuation of violent behavior over time. The scoping review encompassed peer-reviewed articles published in English and Spanish from 2000 to 2019, located through searches carried out in relevant international databases (Web of Science, PsycINFO, Scopus, ERIC, Dialnet Plus). 22 relevant studies were identified. The collected data showed that, in situations of CPV, parents have low levels of perceived self-efficacy and difficulties regulating their emotions, and they display submissive behavior in parent-child interactions. The analyzed articles also described the presence of a negative family climate and a tendency to relativize violent acts perpetrated by children. Lastly, the evidence shows that social relations are altered by mistrust of formal support resources and a certain level of social isolation. The discussion of the obtained results highlights the need for interventions aimed at fostering parenting skills and improving formal support resources to enhance family functioning in situations of CPV.
\end{abstract}

Keywords Child-to-parent violence $\cdot$ Parenting skills $\cdot$ Family functioning $\cdot$ Social support $\cdot$ Scoping review

\section{Introduction}

In recent years, there has been a growing interest in the study of a specific form of intra-family violence: child-to-parent violence (CPV). Although this type of violence shares certain characteristics and many risk factors with other kinds of intra-family violence, CPV is different in that it represents a paradoxical reversal of traditional power roles within the family system, with victims being legally the caretakers of

Bárbara Lorence is a Member of the research group HUM604: Lifestyle development in the life cycle and health promotion of University of Huelva

Bárbara Lorence

bll@us.es

Shirley Arias-Rivera

shiaririv@alum.us.es

Victoria Hidalgo

victoria@us.es

1 Faculty of Psychology, University of Sevilla, C/ Camilo José Cela, s/n, 41018 Sevilla, Spain their aggressors (Tew \& Nixon, 2010). As with other violence-related constructs, such as child maltreatment (MillerPerrin \& Perrin, 2012), there are difficulties and ambiguities in the definition of CPV. The Spanish Society for the Study of Child-to-Parent violence defined it as:

Repeated acts of physical, psychological (verbal or non-verbal) or economic violence by children against their parents or parental figures. The following behaviors are not considered child-to-parent violence: one-off acts of aggression, those perpetrated during a diminished state of awareness that are not repeated once said awareness is recovered (alcohol intoxication, withdrawal syndromes, delirium or hallucination), those caused by psychological disorders (transitory or stable, autism or severe mental disability) and parricide with no prior history of aggression (Pereira et al., 2017, p. 6).

In addition to its continuity over time, CPV differs from other types of violence in that violent acts are commonly used to gain and maintain power and coercive control over parental figures (Aroca-Montolío et al., 2014; Cottrell, 2003; 
Coogan, 2011; Cottrell \& Monk, 2004; Hong et al., 2012; Tew \& Nixon, 2010). Likewise, the assessment of the frequency of abusive behaviors, specially during the last year, allows differentiating them from isolated aggressive acts and determining the levels of severity (Calvete \& Orue, 2016).

Many studies report cases of CPV in its different typologies (physical, psychological and economic) (Rojas-Solís et al., 2016). However, the overall estimation of prevalence rates of $\mathrm{CPV}$ is difficult to establish due to the variability in the use of instruments (Arias-Rivera et al., 2020) and to the established case identification, reporting and recording criteria. Furthermore, there are differences in the prevalence rates of CPV according to age, gender and context (community, judicial or clinical) of the informants (Loinaz \& De Sousa, 2020; Simmons et al., 2018).

According to available empirical data, the median onset age of CPV ranges from 12 to 17 years in most cases (Castañeda et al., 2012; Condry \& Miles, 2014; Contreras \& Cano, 2016; Cottrell \& Monk, 2004; Miles \& Condry, 2016; Pagani et al., 2004). Although there have been recent reports of violent behavior in early and middle childhood highlighting that CPV is not limited to adolescence (Simmons et al., 2020), parents may not identify these behaviors as CPV until their children are older and a pattern of abuse has been established (Hong et al., 2012; Kennair \& Mellor, 2007; Pérez \& Pereira, 2006). Regarding the trajectory that CPV follows throughout adolescence, Simmons et al. (2018) reported that it usually peaks in mid-adolescence and then declines with age. Similarly, Calvete et al., (2020a, 2020b) identified a gradual decrease in abusive behaviors with a peak around age 15. On the other hand, Kuay and Towl (2021) suggests that there are two distinct groups, those whose abusive behavior begins early and persists, and those who have a later onset that dies out over time. It is clear that more studies analyzing CPV from a developmental perspective are needed (Holt, 2016b; Kuay \& Towl, 2021).

In relation to the sex of the parents, recent studies have found that the level of violence directed toward the mother is higher than that directed toward the father (Calvete et al., 2020a, 2020b), in line with previous studies that consistent and significantly point out that the mother is the most physically and psychologically assaulted person (Agnew y Huguley, 1989; Calvete et al., 2013, 2017; Calvete, et al., 2014a; Calvete et al., 2014c; Calvete y Orue, 2016; Condry y Miles, 2014; Gallagher, 2004; Hunter et al., 2010; Ibabe y Jaureguizar, 2011; Pagani et al., 2004, 2009).

In an attempt to understand the genesis and perpetuation of this phenomenon, different theoretical models have been proposed, such as The Social Learning Theory of Bandura and Rivière (1982) (Aroca-Montolío et al., 2012; Izaguirre \& Calvete, 2017; Margolin \& Baucom, 2014), The Reciprocal Coercion Model of Patterson (1983) (Eckstein, 2004; Ibabe et al., 2013; Pagani et al., 2009), The Social
Information Processing Model of Dodge and Pettit (2003) (Calvete et al., 2015a; Contreras \& Cano, 2016), or theories of the juvenile delinquency field (social control, differential association, and strain) (Agnew \& Huguley, 1989). Domestic violence has also been proposed as a conceptual framework to understand this phenomenon, since mothers are more likely than fathers to be abused by their sons (Wilcox, 2012). However, this approach could not be applied in those cases where the daughter is the abuser and the father is the one being abused, in addition to the conflict generated by making the abuser take sole responsibility for his/her crime (Holt, 2016a). In this line, and according to recent findings, the representations of this phenomenon as a form of domestic violence in which the son is labeled as both aggressor and victim could have negative effects on the family system and the possibility of change if a specialized analysis of its contexts and correlations is not carried out (Gabriel et al., 2018; Holt \& Lewis, 2021).

Finally, among the theoretical models that have been proposed to explain CPV, Dutton's Nested Ecological Model (1985) has been also used (Cottrell \& Monk, 2004; Simmons et al., 2018). This model constitute a suitable framework that integrates postulates proposed by previous theoretical models, which also facilitates the analysis of the intervening factors from different ecological levels (Arias-Rivera \& Hidalgo, 2020). From this ecological framework, the purpose of this study is to analyze the available evidence related to some relevant dimensions involved in CPV situations, in particular, in relation to parenting skills, family functioning and social support.

Different parenting skills seem to be impaired in CPV situations. So, different studios have reported parents feel an acute sense of helplessness, paralysis and emotional distress once abusive behaviors are initiated (Gabriel et al., 2018; Selwyn \& Meakings, 2016; Tew \& Nixon, 2010) and, consequently, they show a self-perception of ineffectiveness and inability to cope with educational tasks and responsibilities as parents (Gabriel et al., 2018; Holt, 2011). It has also been reported the existence of a feelings of guilt that hinder the setting of boundaries and the search for solutions (Calvete et al., 2017b; Edenborough et al., 2008; Routt \& Anderson, 2011; Williams et al., 2017). In this line, CPV has been widely related to ineffective parenting practices especially managing appropriate boundaries (Gabriel et al., 2018) and contingent consequences for violent behavior (Calvete et al., 2015c; Del Hoyo et al., 2020). In fact, there is empirical evidence of an association between CPV and authoritarian, inconsistent, and neglectful parenting styles (Calvete et al., 2014a; Calvete et al., 2014c; Castañeda et al., 2012).

In addition to parenting styles, other dimensions of family functioning have also been linked to CPV. Specifically, family cohesion (Beckmann, 2019), a positive emotional climate (Pagani et al., 2003; Zhang et al., 2019) and 
assertive communication (Calvete et al., 2014a; Ibabe \& Bentler, 2016; Ibabe et al., 2013) have all been identified in different studies as protective factors. With respect to the directionality of the relationships, longitudinal studies have confirmed the protective role of positive emotional climate (Pagani et al., 2003), and have indicated that exposure to direct or indirect violence in the nuclear family is a significant risk factor (Arias-Rivera \& Hidalgo, 2020; Beckmann, 2019; Beckmann et al., 2017; Del Hoyo-Bilbao et al., 2017) and predictor of CPV (Calvete, et al., 2020a, 2020b, Calvete et al., 2015b). As consequences of the VPC on family functioning, a distancing of parent-child relationships has been sometimes observed (Murphy-Edwards \& van Heugten, 2018), as well as physical and, in some cases, economic consequences (Murphy-Edwards \& van Heugten, 2018; Paterson et al., 2002).

The presence of CPV also seems to affect parents' relationships with their social environment, particularly in terms of social support. In this sense, there is empirical evidence showing that the isolation (Miles \& Condry, 2015; Moulds et al., 2016), revictimization (Brule \& Eckstein, 2016; Condry \& Miles, 2014; Holt, 2011; Miles \& Condry, 2015; Murphy-Edwards \& van Heugten, 2018; Routt \& Anderson, 2011; Selwyn \& Meakings, 2016; Tew \& Nixon, 2010; Williams et al., 2017) and social stigma (Brule \& Eckstein, 2016) generated by CPV may delay help-seeking; in turn, this may result in the absence of support networks, which are vital to families experiencing this kind of violence (Bonnick, 2019; Edenborough et al., 2008).

Although in recent years a considerable number of empirical studies on these aspects have been conducted and some reviews have been carried out on a more global basis (e.g., Simmons et al., 2018), our understanding remains limited due to the heterogeneity of the variables involved in the development of CPV (Del Hoyo et al., 2020). Due to the complexity of this phenomenon, from an ecological framework, it is important to identify, beyond parenting styles, different dimensions of parenting skills involved in $\mathrm{CPV}$, as well as to analyze other variables that have not been addressed in previous reviews, e.g., social support. Since there are enough empirical studies to draw conclusions on these aspects, the aim of this study was to analyze, through a scoping review, the available evidence regarding parenting skills, family functioning and social support in CPV situations.

\section{Methods}

This scoping review was conducted according to the recommendations of the experts in this methodology (Arksey \& O'Malley, 2005; Daudt et al., 2013; Levac et al., 2010) and the methodological guidelines of Prisma (Moher et al., 2009) and Cochrane (The Cochrane Collaboration, 2011).
The flow chart of the process followed during the search and final selection procedures is shown in Fig. 1.

\section{Inclusion and Exclusion Criteria}

This review included all clinical, community and judicial empirical studies published in either Spanish or English between 2000 and 2019, providing they complied with the following criteria: (a) included a sample of adolescents (10-19 years), both girls and boys, who had perpetrated $\mathrm{CPV}$, or (b) included a sample of parents who, regardless of sex or age, had experienced CPV; and (c) incorporated variables associated with parenting skills, family functioning or social support. It is important to note that the inclusion of studies did not consider the CPV severity threshold. Exclusion criteria were case studies, expert opinions, other variables analyzed, therapeutic experiences, and approaches linked to public policy and police management. Since all the data were extracted from published, peer-reviewed studies, no ethical approval was required.

\section{Search Strategy}

A systematic search of the extant scientific literature was conducted, involving 5 different meta-searches in the following biographic databases: Web of Science, Scopus, PsycINFO, ERIC and Dialnet Plus. The strategy used for the search is shown in Fig. 1 and contemplated a total of 10 terms combined with the Boolean operators OR and NOT. The search was carried out between October 2018 and April 2019 and returned a total of 5449 studies that had been published between 2000 and 2018 .

\section{Study Selection}

The lead author (S.A.) carried out the initial screening process, reading the abstracts and determining whether the studies complied with the inclusion and exclusion criteria. Additional records were obtained using the snowball technique. The Mendeley manager was used to sequentially store the records and remove duplicates. Next, the other authors (V.H. and B.L.) carried out the final selection based on full-text analysis, reaching a consensus in the event of any disagreement.

\section{Assessing the Risk of Bias}

According to Manterola and Otzen (2015), in order to minimize the risk of bias, it is necessary to assess the three pillars that make up any research study: a) what is being measured, b) who is measuring it and c) what it is 
Fig. 1 Flow diagram of data collection and search process steps

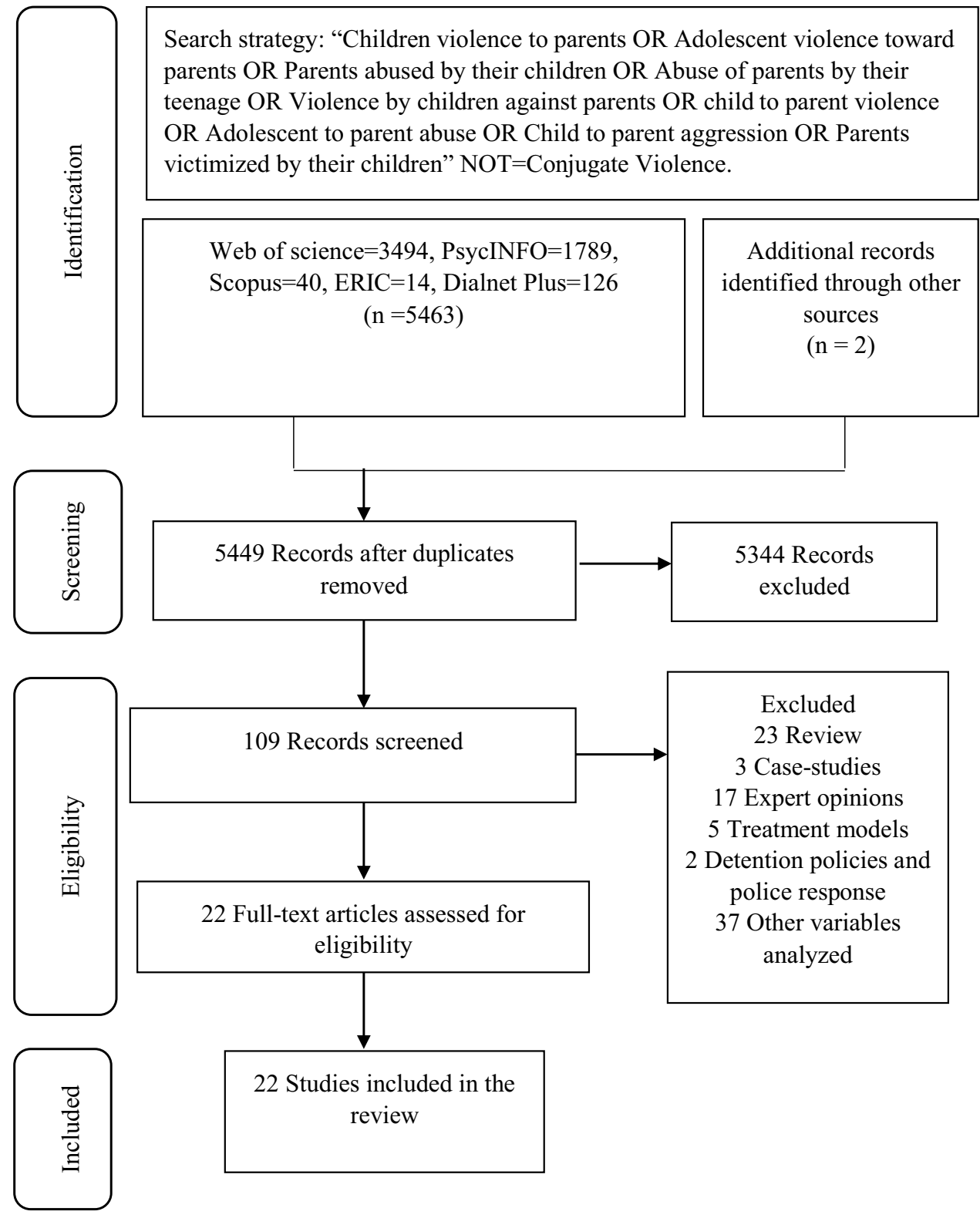

being measured with. In accordance with this strategy, the authors verified that all the studies included in the review:

a)Operationally defined CPV, using adequate sampling strategies and complying with pre-established inclusion and exclusion criteria.

b)Presented data extracted by researchers with the appropriate ethical approval.

c)Used qualitative or quantitative methods and instruments in the data collection process, in accordance with standard methodological guidelines. When there were missing data, it was considered that these did not affect the obtained results.

\section{Data Collection Process}

To attain the objectives of this scoping review, the data were classified and registered on a spreadsheet, which included information about the characteristics of the studies and the results reported (Levac et al., 2010).

\section{Analysis of the Results}

Separate analyses were conducted to describe: 1) the methodological characteristics of the studies included in the review and 2) the results reported regarding parenting skills, family functioning and social support in situations of CPV. 


\section{Results}

\section{Description of the Characteristics of the Empirical Studies}

According to the classification system proposed by Ato et al. (2013), the designs used in the 22 studies included in the review were analyzed in accordance with their manipulation strategy. All the studies had quasi-experimental designs, with 19 being cross-sectional and 3 longitudinal (Table 1). The studies reviewed were carried out in Spain $(\mathrm{n}=8)$, the United Kingdom $(\mathrm{n}=5)$, the United States $(n=3)$, Canada $(n=2)$, New Zealand $(n=2)$, Australia $(n=1)$ and France $(n=1)$. No studies conducted in Latin America were found. Lastly, with respect to the year of publication, 64\% were published over the last six years (2014-2018).

Concerning the characteristics of the study samples, 9 focused on the general population, 6 on the clinical population, 5 on cases brought to the attention of the judicial authorities and 2 on a combined clinical and judicial context. Of the total, $40.9 \%(\mathrm{n}=9)$ collected and analyzed information about both adolescents and parents, 22.7\% $(\mathrm{n}=5)$ focused solely on adolescents, $18.2 \%(\mathrm{n}=4)$ focused solely on parents (of both sexes), $9.1 \%(\mathrm{n}=2)$ only on mothers, $4.5 \%(\mathrm{n}=1)$ on mothers and adolescents and $4.5 \%(\mathrm{n}=1)$ on adoptive parents.

With respect to the type of data analysis carried out, 14 studies conducted qualitative analyses, exploring the content of the participants' discourses, 3 used correlational statistical analyses, 2 employed logistic regression analyses, 1 included a confirmatory factor analysis, and 2 used a structural equation model.

Of the articles analyzed, the majority aimed to explore cognitive-emotional, family, and social characteristics in situations of CPV. Key themes of the qualitative studies included parents' perceptions of their parenting skills and experiences with social support, while the results of the quantitative studies focused on family functioning variables.

Table 2 presents a detailed description of the most important results reported by each of the studies included in the review regarding parenting skills, family functioning and social support.

\section{Reported Evidence for Parenting Skills}

\section{Longitudinal Studies}

With regard to parenting skills, Calvete et al., (2015b), in their longitudinal study, found that the development of
$\mathrm{CPV}$ is significantly associated with the exposure to violence at home and a lack of parental warmth. The analyses evidenced that the lack of parental warmth produced alterations in the cognitive schemas of the adolescents, resulting in behaviors of disconnection and rejection, narcissism, and justification of violence, which in turn predicted an increase in abusive behaviors directed toward both parental figures.

\section{Cross-Sectional Studies}

The cross-sectional studies reported that parents involved in situations of CPV had a low estimation of their self-efficiency as parents (Eckstein, 2004; Edenborough et al., 2008; Holt, 2011; Laurent \& Derry, 1999; Murphy-Edwards \& van Heugten, 2018; Selwyn \& Meakings, 2016; Tew \& Nixon, 2010; Williams et al., 2017) and thereby felt dissatisfied with the way they fulfilled their parental role (Holt, 2011; Selwyn \& Meakings, 2016).

Furthermore, the analyzed studies found that parents involved in situations of CPV often experienced negative emotions associated with parenting role characterized by anxiety, resentment, ambivalence, desperation, impotence and insecurity (Eckstein, 2004; Edenborough et al., 2008; Holt, 2011; Miles \& Condry, 2015; Murphy-Edwards \& van Heugten, 2018; Selwyn \& Meakings, 2016; Tew \& Nixon, 2010; Williams et al., 2017).

In regard to parenting practices, the reviewed articles revealed low levels of control and supervision of children's behavior (Cottrell \& Monk, 2004; Eckstein, 2004; Laurent \& Derry, 1999; Pagani et al., 2003; Selwyn \& Meakings, 2016), with this reduction occurring gradually, until becoming uncontrollable in some cases (Eckstein, 2004; Miles \& Condry, 2015; Selwyn \& Meakings, 2016). In this line, parents involved in situations of CPV were often found to engage in submissive parental behavior which, in many cases, reinforced their children's violent actions (Laurent \& Derry, 1999; Miles \& Condry, 2015; Murphy-Edwards \& van Heugten, 2018; Selwyn \& Meakings, 2016).

The results also identified low levels of communication and affection between the different members of the family (Calvete et al., 2014a; Contreras \& Cano, 2014a), as well as low levels of parental engagement and time spent with their children (Calvete et al., 2014b; Calvete et al., 2015c; Murphy-Edwards \& van Heugten, 2018; Tew \& Nixon, 2010).

Finally, they also highlighted the fact that parents suffering from CPV at home held beliefs and attributions about their children's behaviors that tended to deny, distort, or conceal the violent acts perpetrated by their children against third parties (Calvete et al., 2017; Condry \& Miles, 2014; Cottrell \& Monk, 2004; Holt, 2011; Murphy-Edwards \& van Heugten, 2018; Pagani et al., 2003; Tew \& Nixon, 2010; Williams et al., 2017). 


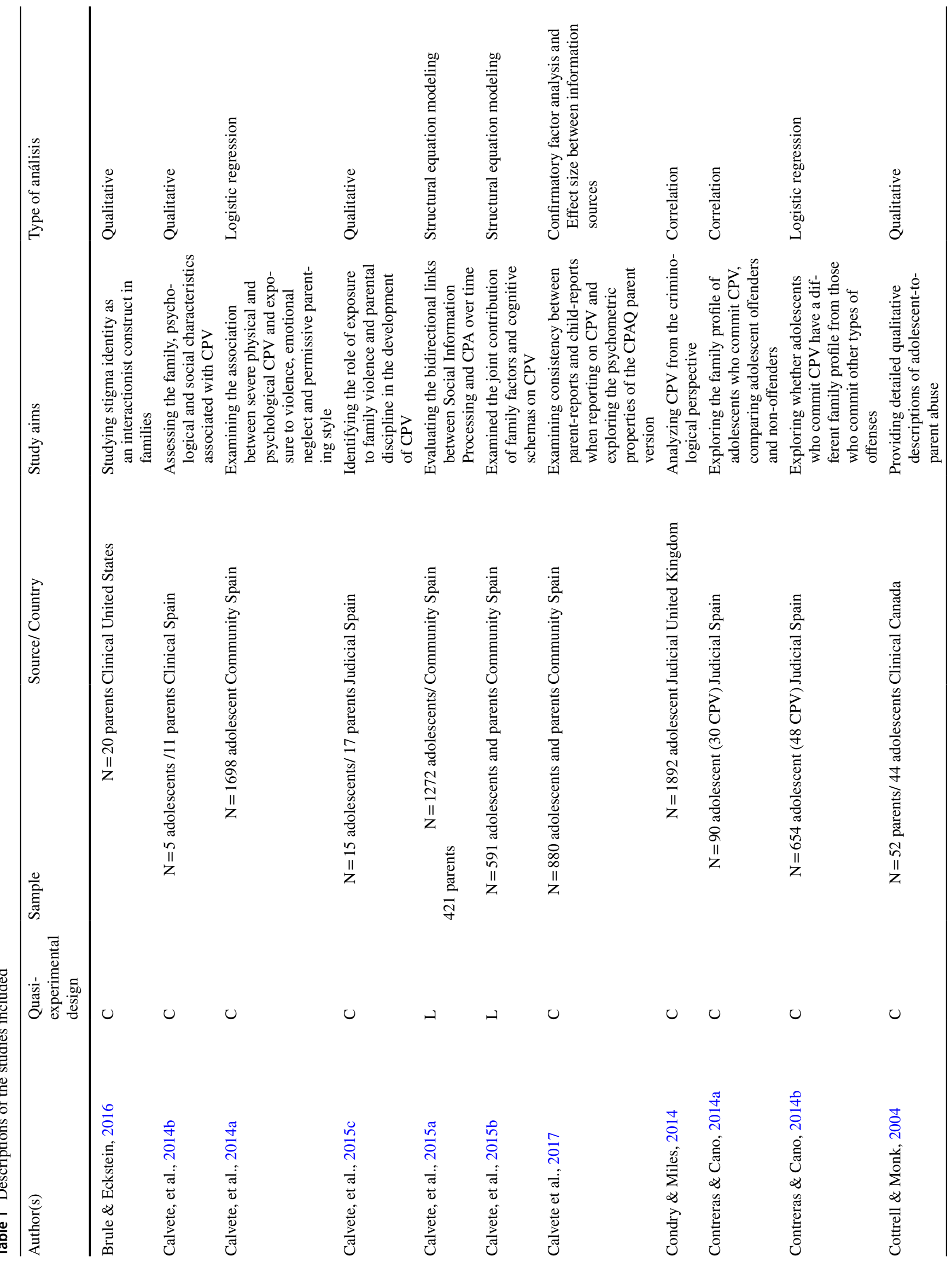




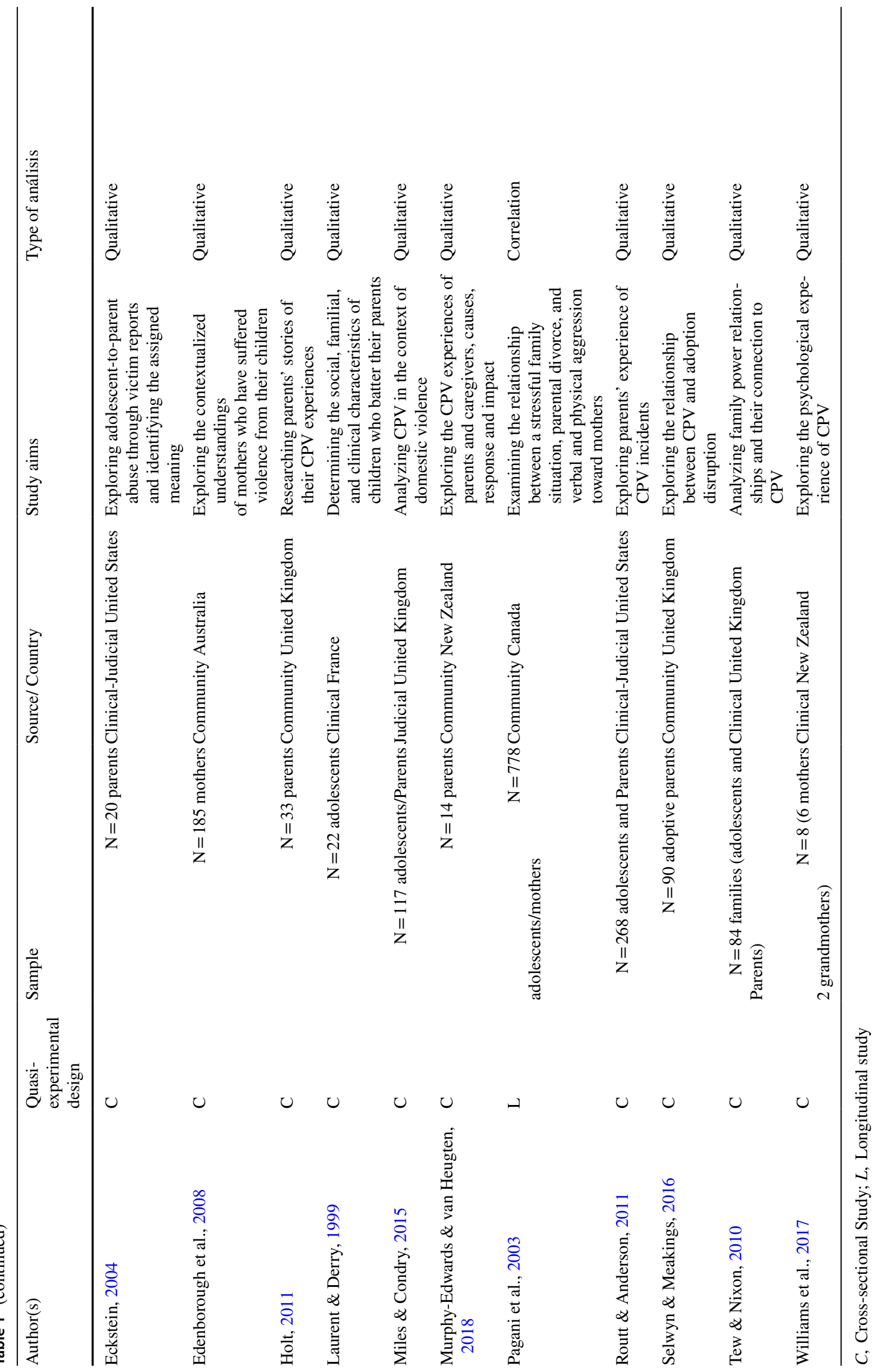


Table 2 Descriptions of parenting skills, family functioning and social support in situations of CPV

\begin{tabular}{|c|c|}
\hline Dimensions & Descriptions \\
\hline \multirow[t]{7}{*}{ Parenting skills } & Parental inefficacy \\
\hline & Negative emotions related to parenting role \\
\hline & Parental dissatisfaction \\
\hline & Low levels of affection and communication \\
\hline & Low levels of inductive control and supervision \\
\hline & Emotional involvement (deprivation) \\
\hline & Submissive parenting \\
\hline
\end{tabular}

Family functioning Co-parenting conflict

Family stress

Transmission of CPV from older to younger siblings Acceptance of parent-child relationships based on violence Changes in family and personal routines

Social support Secondary victimization

Self-imposed social isolation

Perception negative of social support

Social stigma associated with CPV
Author(s)

Calvete, et al., 2015b; Eckstein, 2004; Edenborough et al., 2008; Holt, 2011; Laurent \& Derry, 1999; Murphy-Edwards \& van Heugten, 2018; Selwyn \& Meakings, 2016; Tew \& Nixon, 2010; Williams et al., 2017

Eckstein, 2004; Edenborough et al., 2008; Holt, 2011; Miles \& Condry, 2015; Murphy-Edwards \& van Heugten, 2018; Selwyn \& Meakings, 2016; Tew \& Nixon, 2010; Williams et al., 2017

Holt, 2011; Selwyn \& Meakings, 2016

Calvete, et al., 2014a; Calvete et al., 2015b; Contreras \& Cano, 2014a

Cottrell \& Monk, 2004; Eckstein, 2004; Laurent \& Derry, 1999; Pagani et al., 2003; Selwyn \& Meakings, 2016

Calvete et al., 2014b; Calvete et al., 2015c; Murphy-Edwards \& van Heugten, 2018; Tew \& Nixon, 2010

Laurent \& Derry, 1999; Miles \& Condry, 2015; MurphyEdwards \& van Heugten, 2018; Selwyn \& Meakings, 2016

Calvete et al., 2015a; Calvete et al., 2017; Condry \& Miles, 2014; Cottrell \& Monk, 2004; Holt, 2011; Murphy-Edwards \& van Heugten, 2018; Pagani et al., 2003; Tew \& Nixon, 2010; Williams et al., 2017

Calvete et al., 2015c; Contreras \& Cano, 2014b; Cottrell \& Monk, 2004; Laurent \& Derry, 1999; Pagani et al., 2003

Condry \& Miles, 2014; Cottrell \& Monk, 2004; Edenborough et al., 2008

Contreras \& Cano, 2014a

Eckstein, 2004

Condry \& Miles, 2014; Miles \& Condry, 2015; MurphyEdwards \& van Heugten, 2018; Selwyn \& Meakings, 2016; Tew \& Nixon, 2010

Cottrell \& Monk, 2004; Eckstein, 2004; Edenborough et al., 2008; Holt, 2011; Miles \& Condry, 2015; Murphy-Edwards \& van Heugten, 2018; Selwyn \& Meakings, 2016; Tew \& Nixon, 2010; Williams et al., 2017

Eckstein, 2004; Edenborough et al., 2008; Selwyn \& Meakings, 2016; Tew \& Nixon, 2010; Williams et al., 2017

Cottrell \& Monk, 2004; Edenborough et al., 2008; Holt, 2011; Tew \& Nixon, 2010; Williams et al., 2017

Brule \& Eckstein, 2016; Edenborough et al., 2008; Holt, 2011; Miles \& Condry, 2015; Selwyn \& Meakings, 2016; Tew \& Nixon, 2010

\section{Reported Evidence for Family Functioning}

\section{Longitudinal Studies}

The results of the study of Calvete et al. (2015a) indicated that parental transactional relationships are significant for adolescent externalizing problems such as CPV. Moreover, the CPV predicted changes in several components of social information processing in adolescents by increasing the likelihood of attributing hostility to the social environment, accessing violent cognitive scripts, and anticipating positive consequences of abusive behaviors that, together, modified family dynamics.

The results of Pagani et al. (2003) show that, in general, $\mathrm{CPV}$ is found within a context of parental stress, which leads parental figures to assume permissive or incoherent behaviors that constitute risk factors for the development of CPV.

\section{Cross-Sectional Studies}

The reviewed studies found that CPV tended to coincide with other types of stressful events, such as martial conflict, 
which further complicated the family situation (Calvete et al., 2015c; Contreras \& Cano, 2014b; Cottrell \& Monk, 2004; Laurent \& Derry, 1999).

Some of the analyzed studies found that, in situations of CPV, parents tended to accept violent interactions as normal and the only way of resolving conflicts (Eckstein, 2004). Similarly, some results indicated that violent behavior tended to be replicated by siblings (Contreras \& Cano, 2014b). Parental responses involving the alteration of family and individual routines to avoid confrontation are also observed (Condry \& Miles, 2014; Miles \& Condry, 2015; Murphy-Edwards \& van Heugten, 2018; Selwyn \& Meakings, 2016; Tew \& Nixon, 2010), as well as high levels of family stress (Condry \& Miles, 2014; Cottrell \& Monk, 2004; Edenborough et al., 2008).

Finally, it is worth highlighting that the degree of family breakdown may be extremely severe in situations of CPV, in fact, to such an extent that, in the study of Selwyn and Meakings (2016), which was carried out with adoptive families exposed to this type of violence, the adoption process was disrupted in $50 \%$ of the cases.

\section{Reported Evidence for Social Support}

\section{Longitudinal Studies}

Regarding Social support, an interesting finding was that mothers who sought support through their social network faced a higher risk of verbal and physical abuse by their children (Pagani et al., 2003).

\section{Cross-Sectional Studies}

The analyzed articles reveal that, despite the families' need for social support, parents felt that they were the victims of secondary victimization, since, when they came into contact with law enforcement agents or other professionals, they felt blamed for their children's behavior (Cottrell \& Monk, 2004; Eckstein, 2004; Edenborough et al., 2008; Holt, 2011; Miles \& Condry, 2015; Murphy-Edwards \& van Heugten, 2018; Selwyn \& Meakings, 2016; Tew \& Nixon, 2010; Williams et al., 2017).

Indeed, different studies found that reporting their children's behavior to the police was seen by parents as a last resort, and only occurred after prolonged exposure to violence (Routt \& Anderson, 2011). Some studies also identified other experiences associated with CPV, such as selfimposed social isolation (Eckstein, 2004; Edenborough et al., 2008; Selwyn \& Meakings, 2016; Tew \& Nixon, 2010; Williams et al., 2017), a negative perception of available social support resources (Cottrell \& Monk, 2004; Edenborough et al., 2008; Holt, 2011; Tew \& Nixon, 2010; Williams et al., 2017) and social stigma (Brule \& Eckstein, 2016;
Edenborough et al., 2008; Holt, 2011; Miles \& Condry, 2015; Selwyn \& Meakings, 2016; Tew \& Nixon, 2010).

\section{Discussion}

The aim of this study was to carry out a scoping review to analyze available evidence regarding parenting skills, family functioning and social support in situations of CPV. Using the search strategy described in the Method section, 22 studies were identified to be focused on this issue.

Regarding the methodological characteristics of the identified studies, all had a quasi-experimental design and more qualitative than quantitative data analysis methods were employed. Preferably, cross-sectional studies have been carried out, and few longitudinal studies were identified. Although the cross-sectional studies do not allow for the identification of causal factors, they allow for a detailed description of CPV. Since CPV is a complex relational phenomenon, mixed designs are required to allow for the integration of findings (Tashakkori \& Creswell, 2007), the exploration of causal relationships, and the inclusion of robust statistical analyses to facilitate the identification of mediating and moderating effects (Ato et al., 2013; Baron \& Kenny, 1986; Hair et al., 2014; Hong et al., 2012).

In general, the studies with the largest number of participants were focused on community populations. Participants were diverse, with a large percentage of studies using samples made up of either parents or adolescents alone, despite the clear advantage of multi-informant designs (Achenbach et al., 1987). Moreover, given that it is a relational phenomenon, having information from both parties involved greatly facilitates our understanding of CPV (Condry \& Miles, 2014; Pagani et al., 2004, 2009).

With respect to the origin of the samples, most of the studies included in the review were carried out in Europe and North America. To further our understanding of this phenomenon, it is important to determine its prevalence in other cultures, particularly among the Latin American and Asian populations. Cross-cultural studies would also provide valuable information (Beckmann et al., 2017; Ilabaca \& Gaete, 2018; Moulds et al., 2018).

Studying a complex phenomenon such as CPV entails the risk of reducing its analysis to a limited number of variables in order to describe and understand the relational, social and affective processes underlying this violent behavior, a situation that is expressed in the methodological variability of the studies included in this paper. Generally speaking, the methodological differences observed in the CPV studies made it difficult to analyze the information derived from the obtained data, which made it necessary to identify and report those elements that appeared systematically, in order 
to make it possible to build a cohesive body of scientific knowledge (Simmons et al., 2018).

Secondly, the reviewed studies provided empirical evidence in all three of the analyzed areas: parenting skills, family functioning and social support. In the field of parenting skills, the vast majority of studies found evidence of inadequate parenting practices, mainly characterized by a lack of control and negligence (Cottrell \& Monk, 2004; Eckstein, 2004; Laurent \& Derry, 1999; Pagani et al., 2003; Selwyn \& Meakings, 2016), low levels of affection and communication (Calvete, et al., 2014a; Contreras \& Cano, 2014b) and poor emotional engagement with children (Calvete, et al., 2014b; Murphy-Edwards \& van Heugten, 2018; Tew \& Nixon, 2010). This finding is consistent with that of a recent study by Del Hoyo et al. (2020), who identified a significant relationship between ineffective implementation of parental discipline and CPV.

The close association which exists between parenting practices and CPV is widely supported by empirical evidence; however, it is still unclear as to whether the parenting practices identified are precursors to or the result of the violence perpetrated, due to the lack of longitudinal studies. On the other hand, it is clear that a lack of emotional involvement (deprivation), negative emotions associated with parenting role and communication problems influence the development and continuation of CPV (Calvete, et al., 2014a; Edenborough et al., 2008; Ibabe \& Bentler, 2016; Williams et al., 2017). Based on the above, parenting programs for CPV families should focus on the development of positive parenting styles, especially the demonstration of affection, warmth and support for their children (Calvete, et al., 2015b).

Moreover, the results reported regarding the adoption of submissive behaviors by parents suggest that, in addition to the negative physical, psychological, and economic consequences of $\mathrm{CPV}$, violent acts perpetrated by children may also result in them controlling their parents' behavior (Laurent \& Derry, 1999; Miles \& Condry, 2015; MurphyEdwards \& van Heugten, 2018; Selwyn \& Meakings, 2016).

Alongside inadequate parenting practices, the reviewed studies also reported consistent results regarding parental perceptions of parental ineffectiveness (Eckstein, 2004; Edenborough et al., 2008; Holt, 2011; Laurent \& Derry, 1999; Murphy-Edwards \& van Heugten, 2018; Selwyn \& Meakings, 2016; Tew \& Nixon, 2010; Williams et al., 2017). On some occasions, this low level of perceived selfefficacy led parents to believe that they had completely lost control and thus relented to avoid violent confrontation (Eckstein, 2004; Routt \& Anderson, 2011; Tew \& Nixon, 2010), as well as to establish an even more aggressive circle of interaction with their child in response to their violent behavior (Omer, 2004). These attitudes derived from a lack of security and confidence in their role as parents; far from putting an end to CPV, such attitudes only served to further complicate the situation. Therefore, adolescents sometimes conclude that mistreatment is the only way to interact with their parents (Cottrell \& Monk, 2004; Estévez \& Góngora, 2009).

Given the difficulty of parents in exercising their adequate parenting skills (Edenborough et al., 2008), the intense guilt and shame experienced (Cottrell \& Monk, 2004; Tew $\&$ Nixon, 2010), the exposure to secondary victimization and the lack adequate supports obtained (Miles \& Condry, 2015), it is not surprising that parents hold inaccurate attributions for children's violent behavior and use strategies to deny, distort or hide their children's violent acts, which is an attitude that, in turn, may contribute to the increasing the number of hidden cases (Fernández-González et al., 2021; Kennair \& Mellor, 2007).

Regarding family functioning, the results of the review revealed that CPV is associated with high levels of co-parenting conflict (Calvete, et al., 2015a, 2015b, 2015c; Contreras \& Cano, 2014a; Pagani et al., 2003; Selwyn \& Meakings, 2016), high levels of parental stress (Condry \& Miles, 2014; Cottrell \& Monk, 2004; Edenborough et al., 2008) and changes in everyday routines (Condry \& Miles, 2014; Miles \& Condry, 2015; Murphy-Edwards \& van Heugten, 2018; Selwyn \& Meakings, 2016; Tew \& Nixon, 2010). Likely, these situations, coupled with the fact that parents tend to accept violent interactions as something normal in moments of conflict (Eckstein, 2004), often contribute to generating a negative emotional climate within families experiencing CPV, which in turn increases the risk of the aggressor's siblings replicating violent behavior patterns (Condry \& Miles, 2014; Contreras \& Cano, 2014b).

Lastly, the results found in terms of social support indicate that self-imposed isolation, which seems to be associated with situations of CPV (Eckstein, 2004; Edenborough et al., 2008; Selwyn \& Meakings, 2016; Tew \& Nixon, 2010; Williams et al., 2017), may be explained by the revictimization experienced by parents and the social stigma associated with this type of violence (Brule \& Eckstein, 2016; Condry \& Miles, 2014; Cottrell \& Monk, 2004; Eckstein, 2004; Edenborough et al., 2008; Holt, 2011; Miles \& Condry, 2015; Murphy-Edwards \& van Heugten, 2018; Routt \& Anderson, 2011; Selwyn \& Meakings, 2016; Tew \& Nixon, 2010; Williams et al., 2017).

It would be interesting to explore in future research the role that professionals play in social isolation. The reluctance of parents to contact law enforcement or seek formal social services is a serious problem that needs to be addressed, especially given the role of these institutions in the intervention of these cases (Coogan, 2014; Gallagher, 2004). On the other hand, it is essential to strengthen family care policies and facilitate the availability of social work and mental health professionals (University of Brighton, 2012; 
Wilcox \& Pooley, 2015), considering their high psychosocial risk (Moulds \& Day, 2017).

\section{Limitations}

Although the present review offers a valuable systematization of information based on the identification and exhaustive analysis of existing studies, it nevertheless has some limitations. Firstly, by including only studies published in English and Spanish, the information reported by studies published in other languages was lost. Secondly, the methodological and contextual diversity of the studies required the identification of variability sources and a subgroup analysis.

\section{Conclusions and Practical Implications}

This review provides evidence of the ecological character of $\mathrm{CPV}$, since this investigation was focused on personal, interpersonal and social variables of different ecological systems (Bronfenbrenner \& Morris, 2007). Furthermore, the conclusions of the revised longitudinal studies provide concrete evidence on the transactional nature of this phenomenon.

The results revealed sound empirical evidence regarding the inadequate parenting skills that are associated with CPV, as well the conflictive family relationships that occur due to its presence. Despite their need for support, the data indicate that families in situations of CPV feel a certain amount of mistrust in formal support resources, and the revictimization and social stigma they experience only serve to increase their isolation. Statements made in certain fields and by certain institutions, claiming that parents are always responsible for their children's actions and should always be able to exert power over and control them, do nothing to help visualize the problem in all of its many dimensions, and only serve to conceal the far-reaching consequences of this phenomenon for the families involved.

The results of this systematic review reveal the specific intervention needs of families in a situation of CPV at the personal, family and social levels. In accordance with current initiatives to support and care for families aimed at family training and strengthening, researchers propose the development of preventive and promotional actions that strengthen family systems in adverse conditions (Child Welfare Information Gateway, 2013; Pote et al., 2019), with both adolescent abusers and parents being direct protagonists from a systemic approach (Pereira, 2011, 2019).

Specifically regarding the latter, we want to emphasize the importance of promoting positive parenting programs that favor the acquisition of parenting skills that improve the exercise of parenting in parents experiencing CPV situations (Rodrigo et al., 2009).
Acknowledgements The main author received a grant from the University of Guayaquil for her stay at the University of Seville.

Author Contributions SA conducted the scientific literature review, theoretical justification, methodological design and data collection. BL was the director of analyses and results description. VH coordinated the improvement of the whole design and writing of the paper, including conclusions and research limitations.

Funding Open Access funding provided thanks to the CRUE-CSIC agreement with Springer Nature.

\section{Declarations}

Conflict of Interest The authors declare that the research was conducted in the absence of any commercial or financial relationships that could be construed as a potential conflict of interest.

Open Access This article is licensed under a Creative Commons Attribution 4.0 International License, which permits use, sharing, adaptation, distribution and reproduction in any medium or format, as long as you give appropriate credit to the original author(s) and the source, provide a link to the Creative Commons licence, and indicate if changes were made. The images or other third party material in this article are included in the article's Creative Commons licence, unless indicated otherwise in a credit line to the material. If material is not included in the article's Creative Commons licence and your intended use is not permitted by statutory regulation or exceeds the permitted use, you will need to obtain permission directly from the copyright holder. To view a copy of this licence, visit http://creativecommons.org/licenses/by/4.0/.

\section{References}

Achenbach, T. M., McConaughy, S. H., \& Howell, C. T. (1987). Child/ adolescent behavioral and emotional problems: implications of cross-informant correlations for situational specificity. Psychological Bulletin, 101(2), 213-232. https://doi.org/10.1037/00332909.101.2.213

Agnew, R., \& Huguley, S. (1989). Adolescent violence toward parents. Journal of Marriage and the Family, 51(3), 699-711. 10.2307 / 352169

Arias-Rivera, S., \& Hidalgo, V. (2020). Theoretical framework and explanatory factors for child-to-parent violence A Scoping Review. Anales De Psicologia, 36(2), 220-231. https://doi.org/ 10.6018/analesps.338881

Arias-Rivera, S., Hidalgo, V., \& Lorence, B. (2020). A scoping study on measures of child-to-parent violence. Aggression and Violent Behavior, 52, 101426. https://doi.org/10.1016/j.avb.2020.101426

Arksey, H., \& O'Malley, L. (2005). Scoping studies: hacia un marco metodológico. Revista Internacional de Metodología de La Investigación Social, 8(1), 19-32. 10.1080 / 1364557032000119616

Aroca-Montolío, C., Bellver Moreno, M. C., \& Alba Robles, J. L. (2012). La teoría del Aprendizaje Social como modelo explicativo de la violencia filio-parental. Revista Complutense De Educación, 23(2), 487-511. https://doi.org/10.5209/rev_RCED.2012.v23.n2. 40039

Aroca-Montolío, C., Lorenzo-Moledo, M., \& Miró-Pérez, C. (2014). La violencia filio-parental: Un análisis de sus claves. Anales De Psicologia, 30(1), 157-170. https://doi.org/10.6018/analesps.30.1. 149521

Ato, M., López, J. J., \& Benavente, A. (2013). Un sistema de clasificación de los diseños de investigación en psicología. Anales De 
Psicología, 29, 1038-1059. https://doi.org/10.6018/analesps.29.3. 178511

Bandura, A., \& Rivière, Á. (1982). Teoría del Aprendizaje Social (Espasa Calpe (ed.)).

Baron, R. M., \& Kenny, D. A. (1986). The moderator-mediator variable distinction in social psychological research. conceptual, strategic, and statistical considerations. Journal of Personality and Social Psychology, 51(6), 1173-1182. https://doi.org/10.1037/00223514.51.6.1173

Beckmann, L. (2019). Family relationships as risks and buffers in the link between parent-to-child physical violence and adolescentto-parent physical violence. Journal of Family Violence, 35(2), 131-141. https://doi.org/10.1007/S10896-019-00048-0

Beckmann, L., Bergmann, M. C., Fischer, F., \& Mößle, T. (2017). Risk and protective factors of child-to-parent violence: A comparison between physical and verbal aggression. Journal of Interpersonal Violence, 1-26. https://doi.org/10.1177/0886260517746129

Bonnick, H. (2019). Child to parent violence and abuse : a practitioner's guide to working with families (P. P. and Media (ed.)).

Bronfenbrenner, U., \& Morris, P. A. (2007). The Bioecological model of human development. John Wiley \& Sons, Inc. https://doi.org/ 10.1002/9780470147658.chpsy0114

*Brule, N. J., \& Eckstein, J. J. (2016). "Am I really a bad parent?": Adolescent-to-Parent Abuse (AtPA) identity and the stigma management communication (SMC) model. Journal of Family Communication, 16(3). https://doi.org/10.1080/15267431.2016. 1160908

*Calvete, E., Gámez-Guadix, M., \& Garcia-Salvador, S. (2015a). Social information processing in child-to-parent aggression: Bidirectional associations in a 1-year prospective study. Journal of Child and Family Studies, 24(8), 2204-2216. https://doi.org/ 10.1007/s10826-014-0023-4

*Calvete, E., Gámez-Guadix, M., \& Orue, I. (2014a). Características familiares asociadas a violencia filio-parental en adolescentes. Anales de Psicologia, 30(3), 1176-1182. https://doi.org/10.6018/ analesps.30.3.166291

Calvete, E., Gámez-Guadix, M., Orue, I., Gonzalez-Diez, Z., Lopez de Arroyabe, E., Sampedro, R., Pereira, R., Zubizarreta, A., \& Borrajo, E. (2013). Brief report: The adolescent child-to-parent aggression questionnaire: An examination of aggressions against parents in Spanish adolescents. Journal of Adolescence, 36(6), 1077-1081. https://doi.org/10.1016/j.adolescence.2013.08.017

*Calvete, E., Ibabe, I., Gámez-Guadix, M., \& Bushman, B. J. (2015b). Predictors of child-to-parent aggression : A 3- year longitudinal study. Developmental Psychology, 51(5), 663-676. https://doi.org/ $10.1037 / \mathrm{a} 0039092$

Calvete, E., \& Orue, I. (2016). Violencia filio-parental: Frecuencia y razones para las agresiones contra padres y madres. Psicología Conductual, 24(3), 481-495. https://search.proquest.com/docvi ew/1850699335? accountid=14744

*Calvete, E., Orue, I., Bertino, L., Gonzalez, Z., Montes, Y., Padilla, P., \& Pereira, R. (2014b). Child-to-parent violence in adolescents: The perspectives of the parents, children, and professionals in a sample of spanish focus group participants. Journal of Family Violence, 29, 343-352. https://doi.org/10.1007/s10896-014-9578-5

Calvete, E., Orue, I., Fernández-González, L., Chang, R., \& Little, T. D. (2020a). Longitudinal trajectories of child-to-parent violence through adolescence. Journal of Family Violence, 35(2), 107-116. https://doi.org/10.1007/s10896-019-00106-7

Calvete, E., Orue, I., Fernández-González, L., Chang, R., \& Tood, D. L. (2020b). Longitudinal trajectories of child-to-parent violence through adolescence. Journal of Family Violence, 35, 107-116. https://doi.org/10.1007/s10896-019-00106-7

*Calvete, E., Orue, I., Gámez-Guadix, M., Del Hoyo-Bilbao, J., \& López de Arroyabe, E. (2015c). Child-to-parent violence: an exploratory study of the roles of family violence and parental discipline through the stories told by Spanish children and their parents. Violence and Victims, 30(January), 935-947. https://doi. org/10.1891/0886-6708.VV-D-14-00105

*Calvete, E., Orue, I., \& González-Cabrera, J. (2017). Violencia filio parental : comparando lo que informan los adolescentes y sus progenitores. Revista de Psicología Clínica Con Niños y Adolescentes, 4(1), 9-15. https://dialnet.unirioja.es/descarga/articulo/ 5789314.pdf. Accessed 12 Oct 2018

Calvete, E., Orue, I., \& Sampedro, R. (2014c). Violencia filio-parental en la adolescencia : Características ambientales y personales. Infancia y Aprendizaje., 34(3), 349-363. https://doi.org/10.1174/ 021037011797238577

Castañeda, A., Garrido-Fernández, M., \& Lanzarote, M.-D. (2012). Menores con conducta de maltrato hacia los progenitores : Un estudio de personalidad y estilos de socialización. Revista De Psicología Social, 27(2), 157-167. https://doi.org/10.1174/02134 7412800337933

Child Welfare Information Gateway. (2013). Parent Education to Strengthen Families and Reduce the Risk of Maltreatment. https://www.childwelfare.gov

*Condry, R., \& Miles, C. (2014). Adolescent to parent violence: Framing and mapping a hidden problem. Criminology and Criminal Justice, 14(3), 257-275. https://doi.org/10.1177/ 1748895813500155

*Contreras, L., \& Cano, C. (2014a). Family profile of young offenders who abuse their parents: A comparison with general offenders and non-offenders. Journal of Family Violence, 29(8), 901910. https://doi.org/10.1007/s10896-014-9637-y

*Contreras, L., \& Cano, M. C. (2014b). Adolescents who assault their parents: A different family profile of young offenders? Violence and Victims, 29(3), 393-406. https://doi.org/10.1891/ 0886-6708.VV-D-12-00132

Contreras, L., \& Cano, M. C. (2016). Child-to-parent violence : The role of exposure to violence and its relationship to social-cognitive processing. The European Journal of Psychology Applied to Legal Context, 8(2), 43-50. https://doi.org/10.1016/j.ejpal. 2016.03.003

Coogan, D. (2011). Child-to-parent violence: Challenging perspectives on family violence. Child Care in Practice, 17(4), 347358. https://doi.org/10.1080/13575279.2011.596815

Coogan, D. (2014). Responding to child-to-parent violence: Innovative practices in child and adolescent mental health. Health and Social Work, 39(2), 1-9. https://doi.org/10.1093/hsw/hlu011

Cottrell, B. (2003). Parent abuse: The abuse of parents by their teenage children. National Clearinghouse on Family Violence, 1-10.

*Cottrell, B., \& Monk, P. (2004). Adolescent-to-Parent Abuse. A Qualitative Overview of Common Themes. Journal of Family Issues, 25(8), 1072-1095. https://doi.org/10.1177/0192513X03261330

Daudt, H. M. L., Van Mossel, C., \& Scott, S. J. (2013). Enhancing the scoping study methodology: A large, inter-professional team's experience with Arksey and O'Malley's framework. BMC Medical Research Methodology, 13(1), 1. https://doi.org/10.1186/ 1471-2288-13-48

Del Hoyo-Bilbao, J., Gámez-Guadix, M., \& Calvete, E. (2017). Corporal punishment by parents and child-to-parent aggression in Spanish adolescents. Anales De Psicología, 34(1), 108. https:// doi.org/10.6018/analesps.34.1.259601

Del Hoyo, J., Orue, I., Gámez-Guadix, M., \& Calvete, E. (2020). Multivariate models of child-to-mother violence and child-to-father violence. The European Journal of Psychology Applied to Legal Context, 12, 11-21. https://journals.copmadrid.org/ejpalc/art/ejpal c2020a2. Accessed 20 Apr 2021

Dodge, K. A., \& Pettit, G. S. (2003). A biopsychosocial model of the development of chronic conduct problems in adolescence. Developmental Psychology, 39(2), 349-371. https://doi.org/10.1037/ 0012-1649.39.2.349 
Dutton, D. (1985). An ecologically nested theory of male violence toward intimates. International Journal of Women's Studies, 8, 404-413.

*Eckstein, N. J. (2004). Emergent issues in families experiencing adolescent-to-parent abuse. Western Journal of Communication, 68(4), 365-388. https://doi.org/10.1080/10570310409374809

*Edenborough, M., Jackson, D., Mannix, J., \& Wilkes, L. M. (2008). Living in the red zone: The experience of child-to-mother violence. Child and Family Social Work, 13(4), 464-473. https://doi. org/10.1111/j.1365-2206.2008.00576.x

Estévez, E., \& Góngora, J. N. (2009). Adolescent aggression towards parents: Factors associated and intervention proposals. In Universidad de Valencia (Ed.), Handbook of Aggressive Behavior Research (pp. 143-164). Caitriona Quin and Scott Tawse. https://www.uv.es/lisis/estevez/handbook-agresive-behav. pdf. Accessed 11 Jul 2017

Fernández-González, L., Orue, I., Adrián, L., \& Calvete, E. (2021). Child-to-parent aggression and dating violence: Longitudinal associations and the predictive role of early maladaptive schemas. Journal of Family Violence, 2021, 1-9. https://doi.org/10. 1007/S10896-021-00269-2

Gabriel, L., Tizro, Z., James, H., Cronin-Davis, J., Beetham, T., Corbally, A., Lopez-Moreno, E., \& Hill, S. (2018). "Give me some space": Exploring youth to parent aggression and violence. Journal of Family Violence, 33(2), 161-169. https://doi. org/10.1007/s10896-017-9928-1

Gallagher, E. (2004). Youth who victimise their parents. Australian and New Zealand Journal of Family Therapy, 25(2), 94-105. https://doi.org/10.1002/j.1467-8438.2004.tb00591.x

Hair, J. F., Black, W. C., Babin, B. J., \& Anderson, R. E. (2014). Multivariate data analysis. Pearson Custom Library. https://doi. org/10.1038/259433b0

*Holt, A. (2011). "The terrorist in my home": Teenagers' violence towards parents - constructions of parent experiences in public online message boards. Child and Family Social Work, 16(4), 454-463. https://doi.org/10.1111/j.1365-2206.2011.00760.x

Holt, A. (2016a). Adolescent-to-parent abuse as a form of "Domestic Violence": A conceptual review. Trauma, Violence, \& Abuse, 17(5), 490-499. https://doi.org/10.1177/1524838015584372

Holt, A. (2016b). Working with adolescent violence and abuse towards parents : approaches and contexts for intervention (Routledge (ed.)).

Holt, A., \& Lewis, S. (2021). Constituting child-to-parent violence: Lessons from England and Wales. The British Journal of Criminology. https://doi.org/10.1093/bjc/azaa088

Hong, J. S., Kral, M. J., Espelage, D. L., \& Allen-Meares, P. (2012). The social ecology of adolescent-initiated parent abuse: A review of the literature. Child Psychiatry \& Human Development, 43(3), 431-454. https://doi.org/10.1007/ s10578-011-0273-y

Hunter, C., Nixon, J., \& Parr, S. (2010). Mother abuse: A matter of youth justice, child welfare or domestic violence? Journal of Law and Society, 37(2), 264-284. https://doi.org/10.1111/j. 1467-6478.2010.00504.x

Ibabe, I., \& Bentler, P. M. (2016). The contribution of family relationships to child-to-parent violence. Journal of Family Violence, 31(2), 259-269. https://doi.org/10.1007/ s10896-015-9764-0

Ibabe, I., \& Jaureguizar, J. (2011). ¿Hasta qué punto la violencia filioparental es bidireccional? Anales de Psicologia, 27(2), 265-277. http://www.redalyc.org/pdf/167/16720051001.pdf

Ibabe, I., Jaureguizar, J., \& Bentler, P. M. (2013). Protective factors for adolescent violence against authority. Revista Española De Psicología, 16(76), 1-13. https://doi.org/10.1017/sjp.2013.72

Ilabaca, P., \& Gaete, J. (2018). Adolescents who are violent toward their parents: An approach to the situation in Chile. Journal of
Interpersonal Violence, 088626051880885. https://doi.org/10. $1177 / 0886260518808856$

Izaguirre, A., \& Calvete, E. (2017). Exposure to family violence as a predictor of dating violence and child-to-parent aggression in Spanish Adolescents. Youth \& Society, 49(3), 393-412. https:// doi.org/10.1177/0044118X16632138

Kennair, N., \& Mellor, D. (2007). Parent abuse: A review. Child Psychiatry and Human Development, 38(3), 203-219. https://doi.org/ 10.1007/s10578-007-0061-x

Kuay, H. S., \& Towl, G. (2021). Child to parent aggression and violence. A guidebook for parents and practitioners (Routledge (ed.); 1st ed.). https://doi.org/10.4324/9780429259562

*Laurent, A., \& Derry, A. (1999). Violence of French Adolescents Toward Their Parents : Characteristics and Contexts. Journal of Adolescent Health, 25, 21-26. https://doi.org/10.1016/S1054139X(98)00134-7

Levac, D., Colquhoun, H., \& O'Brien, K. K. (2010). Scoping studies: Advancing the methodology. Implementation Science, 5(1), 1-9. https://doi.org/10.1186/1748-5908-5-69

Loinaz, I., \& De Sousa, A. (2020). Assessing risk and protective factors in clinical and judicial child-to-parent violence cases. The European Journal of Psychology Applied to Legal Context, 12(1), 43-51. https://doi.org/10.5093/ejpalc2020a5

Manterola, C., \& Otzen, T. (2015). Los Sesgos en Investigación Clínica. International Journal of Morphology, 33(3), 11561164. https://scielo.conicyt.cl/pdf/ijmorphol/v33n3/art56.pdf. Accessed 14 Apr 2019

Margolin, G., \& Baucom, B. R. (2014). Adolescents' aggression to parents: Longitudinal links with parents' physical aggression. Journal of Adolescent Health, 55(5), 645-651. https://doi.org/ 10.1016/j.jadohealth.2014.05.008

*Miles, C., \& Condry, R. (2015). Responding to adolescent to parent violence: Challenges for policy and practice. British Journal of Criminology, 55(6), 1076-1095. https://doi.org/10.1093/bjc/ azv095

Miles, C., \& Condry, R. (2016). Adolescent to parent violence : The police response to parents reporting violence from their children. Policing and Society, 26(7), 804-823. https://doi.org/10. 1080/10439463.2014.989158

Miller-Perrin, C., \& Perrin, R. (2012). Child maltreatment an introduction (SAGE Publishing (ed.); Third Edit). https:// uk.sagepub.com/en-gb/eur/child-maltreatment/book235625. Accessed 23 Jan 2021

Moher, D., Liberati, A., Tetzlaff, J., Altman, D. G., Altman, D., Antes, G., Atkins, D., Barbour, V., Barrowman, N., Berlin, J. A., Clark, J., Clarke, M., Cook, D., D’Amico, R., Deeks, J. J., Devereaux, P. J., Dickersin, K., Egger, M., Ernst, E., ... Tugwell, P. (2009). Preferred reporting items for systematic reviews and meta-analyses: The PRISMA statement. PLoS Medicine, 6(7). https://doi.org/10.1371/journal.pmed.1000097

Moulds, L., \& Day, A. (2017). Characteristics of adolescent violence towards parents - a Rapid Evidence Assessment. Journal of Aggression, Conflict and Peace Research, 9(3), 195-209. https://doi.org/10.1108/JACPR-11-2016-0260

Moulds, L., Day, A., Mayshak, R., Mildred, H., \& Miller, P. (2018). Adolescent violence towards parents- Prevalence and characteristics using Australian Police Data. Australian \& New Zealand Journal of Criminology, 1-19. http://journals.sagepub. com.us.debiblio.com/doi/pdf/https://doi.org/10.1177/00048 65818781206

Moulds, L., Day, A., Mildred, H., Miller, P., \& Casey, S. (2016). Adolescent violence towards parents - the known and unknowns. Australian and New Zealand Journal of Family Therapy, 37(4), 547-557. https://doi.org/10.1002/anzf.1189

*Murphy-Edwards, L., \& van Heugten, K. (2018). Domestic property violence: A distinct and damaging form of parent abuse. 
Journal of Interpersonal Violence, 33(4), 617-636. https://doi. org/10.1177/0886260515613341

Omer, H. (2004). Nonviolent resistance. A new approach to violent and self-destructive children (Cambridge (ed.)). Cambridge University Press.

*Pagani, L., Larocque, D., Vitaro, F., \& Tremblay, R. E. (2003). Verbal and physical abuse toward mothers: The role of family configuration, environment, and coping strategies. Journal of Youth and Adolescence, 32(3), 215-222. https://doi.org/10. 1023/A:1022599504726

Pagani, L., Tremblay, R. E., Nagin, D., Zoccolillo, M., Vitaro, F., \& McDuff, P. (2009). Risk factor models for adolescent verbal and physical aggression toward fathers. Journal of Family Violence, 24, 173-182. https://doi.org/10.1007/s10896-008-9216-1

Pagani, L., Tremblay, R., Nagin, D., Zoccolillo, M., Vitaro, F., \& Mcduff, P. (2004). Risk factor models for adolescent verbal and physical aggression toward mothers. International Journal of Behavioral Development, 28(6), 528-537. https://doi.org/10. 1080/01650250444000243

Paterson, R., Luntz, H., Perlesz, A., \& Cotton, S. (2002). Adolescent violence towards parents: Maintaining family connections when the going gets tough. Australian and New Zealand Journal of Family Therapy, 23(2), 90-100. https://doi.org/10.1002/j.14678438.2002.tb00493.x

Patterson, G., \& Wells, K. (1984). A social learning approach: Coercive family process. Behavior Therapy, 15(1), 121-127. https://doi.org/ 10.1016/S0005-7894(84)80046-5

Pereira, R. (2011). Psicoterapia de la violencia filio-parental: Entre el secreto y la verguenza (Morata).

Pereira, R. (2019). La intervención en VFP desde el modelo sistémico. In Alianza (Ed.), La violencia flio-parental. Análisis, evaluación e intervención (pp. 163-202).

Pereira, R., Loinaz, I., Del Hoyo-Bilbao, J., Arrospide, J., Bertino, L., Calvo, A., Montes, Y., \& Gutiérrez, M. M. (2017). Propuesta de definición de violencia filio-parental: Consenso de la Sociedad Española para el Estudio de la Violencia Filio-Parental (SEVIFIP). Papeles Del Psicologo, 1-9. https://doi.org/10.23923/pap. psicol2017.2839

Pérez, T., \& Pereira, R. (2006). Violencia filio-parental: revisión de la bibliografía. Revista Mosaico, 36, 1-13. https://revistamosaico. featf.org/downloads/mosaico-36-violencia-filio-parental-padresmaltratados-por-sus-hijos/. Accessed 22 Sept 2017

Pote, I., Doubell, L., Brims, L., Larbie, J., Stock, L., Lewing, B., Asmussen, K., Taylor, S., Berry, V., Challis, A., Penman, M., Rhodes, H., Symonds, J., Thomas, H., \& Walker, J. (2019). Engaging disadvantaged and vulnerable parents: an evidence review. Early Intervention Foundation, April, 1-93. https://www. eif.org.uk/files/pdf/engaging-disadvantaged-vulnerable-parents. pdf. Accessed 22 May 2021

Rodrigo, M. J., Martín Quintana, J. C., Cabrera Casimiro, E., \& Máiquez Chaves, M. . L. (2009). Las competencias parentales en Contextos de Riesgo Psicosocial. Psychosocial Intervention, 18(2), 113-120. http://scielo.isciii.es/scielo.php?script=sci_artte xt\&pid=S1132-05592009000200003. Accessed 29 Aug 2019

Rojas-Solís, J., Vázquez-Aramburu, G., \& Llamazares-Rojo, J. (2016). Violencia filio-parental: Una revisión de un fenómeno emergente en la investigación psicológica [Child-to-Parent Violence: A review of an emerging phenomenon in psychological research]. Ajayu Órgano de Difusión Científica Del Departamento de Psicología UCBSP, 14(1), 140-161. https://www.aacademica. org. Accessed 20 May 2021

*Routt, G., \& Anderson, L. (2011). Adolescent violence towards parents. Journal of Aggression, Maltreatment \& Trauma, 20(1), 1-19. https://doi.org/10.1080/10926771.2011.537595

*Selwyn, J., \& Meakings, S. (2016). Adolescent-to-parent violence in adoptive families. British Journal of Social Work, 46(5), 1224 1240. https://doi.org/10.1093/bjsw/bcv072

Simmons, M., McEwan, T. E., \& Purcell, R. (2020). A social-cognitive investigation of young adults who abuse their parents. Journal of Interpersonal Violence, 088626052091555 . https://doi.org/10. 1177/0886260520915553

Simmons, M., McEwan, T. E., Purcell, R., \& Ogloff, J. R. P. (2018). Sixty years of child-to-parent abuse research: What we know and where to go. Aggression and Violent Behavior, 38, 31-52. https:// doi.org/10.1016/J.AVB.2017.11.001

Tashakkori, A., \& Creswell, J. W. (2007). Editorial: Exploring the nature of research questions in mixed methods research. Journal of Mixed Methods Research, 1(3), 207-211. https://doi.org/10. $1177 / 1558689807302814$

*Tew, J., \& Nixon, J. (2010). Parent abuse: Opening up a discussion of a complex instance of family power relations. Social Policy and Society, 9(04), 579-589. https://doi.org/10.1017/S147474641 0000291

The Cochrane Collaboration. (2011). Manual Cochrane de revisiones sistemáticas de intervenciones (J. Higgins \& S. Grenn (eds.); 5.1, pp. 1-639). www.cochrane-handbook.org.

University of Brighton. (2012). Respondiendo a la violencia entre padres e hijos. Kit de Herramientas de Daphne. https://ec.europa. eu/justice/grants/results/daphne-toolkit/content/responding-childparent-violence_en. Accessed 03 May 2021

Wilcox, P. (2012). Is parent abuse a form of domestic violence? Social Policy \& Society, 11(2), 277-288. https://doi.org/10.1017/S1474 746411000613

Wilcox, P., \& Pooley, M. (2015). Responding to child to parent violence \& abuse in Europe. Research and data mapping -workstream 1. In D. Programme (Ed.), Research and data mapping -workstream 1. www.rcpv.eu/71-rcpv-ws1-report-final-1-may-zipped. Accessed 19 Jul 2017

*Williams, M., Tuffin, K., \& Niland, P. (2017). "It's like he just goes off, BOOM!": mothers and grandmothers make sense of child-toparent violence. Child and Family Social Work, 22(2), 597-606. https://doi.org/10.1111/cfs.12273

Zhang, L., Cai, C., Wang, Z., Tao, M., Liu, X., \& Craig, W. (2019). Adolescent-to-mother psychological aggression: The role of father violence and maternal parenting style. Child Abuse \& Neglect, 98 , 104229. https://doi.org/10.1016/J.CHIABU.2019.104229

Publisher's Note Springer Nature remains neutral with regard to jurisdictional claims in published maps and institutional affiliations. 